\title{
Self-regulation across time of first-generation online learners
}

\author{
Lucy Barnard-Brak ${ }^{\mathrm{a} *}$, Valerie Osland Paton ${ }^{\mathrm{b}}$ and William Y. Lan ${ }^{\mathrm{b}}$ \\ ${ }^{a}$ Educational Psychology, Baylor University, Waco, Texas, USA; ${ }^{b}$ Texas Tech University, \\ Lubbock, Texas, USA
}

(Received 7 September 2008; final version received 9 June 2009)

\begin{abstract}
Self-regulatory skills have been associated with positive outcomes for learners. In the current study, we examined the self-regulatory skills of students who are firstgeneration online learners over the course of their first semester of online instruction. The purpose of this study is to determine whether the online selfregulatory skills of learners changed across time as associated with being immersed in their first online learning environment. The results of the current study indicate no significant differences in the online self-regulatory skills of learners across time. Results suggest that environmental factors such as being immersed in an online learning environment for the first time is not, in and of itself, associated with the development of self-regulatory skills of online learners. We conclude that the design of online courses needs to consider ways of developing self-regulatory skills as these skills are not automatically developed with students' online learning experiences.
\end{abstract}

Keywords: self-regulation; online learning

\section{Introduction}

Today's students are among the first generation of online learners. First-generation online learners refer to those learners whose parents and preceding generations did not learn via the Internet. Given the age frame of the participants in the current study, none of the parents or preceding generations of the participants could have learnt online. These first-generation online learners manage issues that their traditional, face-to-face counterparts do not. One of these issues is the self-regulation of their learning process. The development of self-regulation skills in online learning is especially crucial for two reasons. First, online learning environments have been noted as requiring students to employ more self-regulatory skills (Fisher and Baird 2005; Ally 2004). Second, self-regulatory skills have been noted as being positively associated with academic achievement (Nota, Soresi, and Zimmerman 2004; Schunk and Zimmerman 1998; Zimmerman and Schunk 2001). The engagement of these selfregulatory skills refers to those volitional behaviours on the part of the individual to regulate, manage, and navigate a situation or environment successfully. Therefore, the study of self-regulation in online learners is especially relevant to the academic success of this first generation of online learners.

This study was an examination of the self-regulation of students who are firstgeneration online learners over the period of their first semester of online instruction.

*Corresponding author. Email: lucy_barnard-brak@baylor.edu 
Self-regulation of learning in the online versus face-to-face learning environments is fundamentally different as these students in the online learning environment must be more autonomous and proactive in their learning given the decreased interaction with instructors or peers (Ally 2004). Thus, students in the online learning environment must engage in self-regulated learning behaviours more frequently. As such, there is a distinct body of literature that examines self-regulation in the online learning environment (for example, Ally 2004; Barnard, Lan, et al. 2008, 2009; Barnard, Paton, and Lan 2008; Fisher and Baird 2005). The purpose of this study was to determine whether the online self-regulatory skills of learners changed across time as associated with being immersed in their first online learning environment. The context of learning, including learning environments, has been suggested as influencing the way students approach their learning. The effects of environment on learning have often been assumed and, thus, rarely examined in empirical research (Severiens, Ten Dam, and Wolters, 2001). Meece (1994) has noted that there is a need to examine the longitudinal stability of self-regulation in learning over time. Vermetten, Vermunt, and Lodewijks (1999) have echoed this sentiment and documented the scarcity of longitudinal research regarding the learning strategies of students in higher education. This paucity of research would indicate the need for further examination of selfregulation of online learners across time. However, in measuring a construct related to the online self-regulation of learners, Arbaugh found "... little to no significant change in students' perceptions of online learning between their first online course and subsequent online courses ..." $(2004,169)$. Students' perceptions of online learning may be related to their self-regulatory skills in online learning, but this finding does not provide information as to the development of self-regulatory skills in online learning.

From a social cognitive perspective, the interaction of personal, behavioural, and environmental factors have been suggested as influencing the development of selfregulation across time (Bandura 1986, 1997; Schunk 2001; Zimmerman 1994). The form of the developmental process of self-regulation has been indicated as being cyclical in nature (Schunk 2001). The cyclical nature of this process would suggest that each of these factors (e.g. personal, behavioural, and environmental) would change and adjust through each cycle. Thus, at each stage of the cycle, students' learning would interact with these factors, which would lead to changes in their learning strategies and behaviours (Bandura 1986, 1997). In line with the cyclical view of the development of self-regulation, Zimmerman (1998) proposed a three-phase model. The first phase, the forethought phase, refers to motivational and strategic processes that precede and set the stage for performance - including, but not limited to: goalsetting; attribution; self-efficacy of the undertaking tasks; and the intrinsic motivation to perform the task. The second phase, the performance control or volitional phase, consists of those processes during learning such as attention, affect, and monitoring action. In the third and final phase, the self-reflection phase, individuals respond to their efforts by monitoring the outcomes of their performance. For example, an individual may have the forethought of goal-setting as part of the first phase. Yet, during the actual performance of the attempted goal-related task, individuals will make social comparisons by attending to the performance of others they view as similarly situated. During the third and final self-reflection phase, the individual will self-evaluate based upon these social comparisons and adjust their forethought for the next task. This social cognitive perspective on the development of self-regulation in learning presents a theoretical framework from which these skills may be viewed. 
In viewing the development of self-regulated online learning behaviours from a social cognitive perspective, Schunk (2001) notes that self-regulated learning behaviours in general initially develop from the influence of environmental factors rather than the influence of personal or behavioural factors. Across time, the influential source in the development of self-regulation will shift from these environmental factors to more personal factors as the skill or behaviour becomes more internalised by the individual rather than being socially or environmentally influenced (Schunk 2001). Thus, for first-generation online learners in their first semester of their respective online degree programmes, the development of self-regulated learning behaviours would appear to initially develop from the influence of environmental factors such as through the online learning environment. Furthermore, Schunk indicates that these self-regulated behaviours are "highly context dependent" $(2001,125)$ such that the development of self-regulated learning behaviours in online environments must be examined exclusively as these behaviours will not develop equally across all domains or in all learning situations. With regard to the time that these behaviours would take to develop, a student's self-regulated learning behaviours would appear to modify as they receive feedback from their graded assignments, examinations, instructor, and even other students as to their performance in the course under a social cognitive perspective. Thus, in view of this theoretical perspective, the self-regulated learning behaviours of a student could change quite quickly depending upon the context of the learning environment.

In examining recent extant research regarding self-regulation in the online learning environment, Lynch and Dembo (2004) examined the relationship between selfregulation and online learning in a blended learning context. While the results of Lynch and Dembo (2004) did not indicate a strong relationship between self-regulated learning skills and academic performance in the online learning environment, they noted that their sample appeared to be highly self-regulated and future research would have to re-examine this relationship between self-regulation and online learning performance. Barnard, Paton, and Lan (2008) found that these self-regulated learning skills appeared to function as a mediator in the relationship between course perceptions and academic achievement in the online learning environment. In examining these skills as a mediator, Barnard, Lan et al. (2008) further examined the relationship between epistemological beliefs and online self-regulated learning skills, indicating that these self-regulated learning skills in the online learning environment act as a mediating variable in the relationship between epistemological beliefs and academic achievement.

The purpose of this study is to examine the development of self-regulated learning behaviours in an online learning environment across the first semester of enrolment in an online degree programme. The online course matriculation itself is the intervention or phenomenon examined as without supplemental intervention with regard to selfregulated learning skills or behaviours. While we assume that these participants choosing to enrol into a course with an online format would be at least somewhat familiar and comfortable with the online environment, none of the participants in the current study had ever enrolled in an online course. In this sense, we examined the self-regulated learning behaviours of participants before and after matriculating in the online learning environment without the introduction of any specific intervention as to these skills. To achieve this purpose, we examined two research questions to achieve the purpose of the study. The first research question concerns whether the overall self-regulatory skills of students enrolled in their first semester of online 
courses would significantly change over the course of the semester. The examination of this first research question would suggest the importance of the context of the learning environment as influencing the development of self-regulatory skills. This finding would provide evidence towards the social cognitive perspective of self-regulation as developing from the cyclical interaction of personal, behavioural, and environmental factors, especially with respect to those environmental factors such as context of the learning environment. The second research question concerns whether certain subsets of self-regulatory skills of students enrolled in their first semester of online courses would significantly change over the course of a semester. First-generation online learners were chosen as the unit for analysis as the current generation represents the first generation of individuals who not only interact with an online environment but formally learn in this environment. As such, the self-regulation of these individuals before and after their matriculating online is particularly worthy of study. These firstgeneration online learners are not only the first generation of world web users but also the first generation of individuals who access formal higher education through the online learning environment.

\section{Method}

\section{Participants}

We sampled from a population of all students enrolled in their first semester of programmes offered online at a large, public university located in the southwestern United States. This sampling frame consisted of 209 students with unduplicated, deliverable email addresses. These students were contacted to complete a pre survey online within the first four weeks of the semester and then a post survey online during the last four weeks of the semester. Of those 209 students, 101 students completed the pre survey. Of those 101 students who completed the pre survey, 44 also completed the post survey. Across the two data collection time points, the resulting response rate was approximately $21 \%$. In performing a priori power analyses for a paired-sample dependent $t$-test, analyses indicate power $(1-\beta)$ of 0.81 and with $\alpha=0.05$ may be achieved by a sample of 34 respondents. Among those students who completed both the pre and post surveys, approximately $77 \%(n=34)$ were female while approximately $70 \%(n$ $=31)$ identified themselves as white and approximately $21 \%(n=9)$ identified themselves as Hispanic. The ethnic distribution of students may be considered typical for students matriculating at the university studied. The student gender distribution may also be considered representative of those students who are enrolled in programmes offered online or at a distance across the United States (Digest of Educational Statistics 2007; Kamarae 2001). Respondents were enrolled in 14 different academic degree programmes and listed home addresses in 21 different US postal zip codes. The average age of students in the sample was approximately 39.55 years old (standard deviation $=10.11$ ), ranging from 18 years old to 55 years old. While students enrolled in courses offered online or at a distance have been indicated as being typically older than traditionally enrolled students (Digest of Educational Statistics 2007), age may have an impact on the self-regulated learning behaviours of students, which we should note. We should also note that the definition of a generation appears to be very much culturally bound. For instance, in contemporary western culture, women typically start having children at an older age. As such, the length of a generation is typically longer (e.g. 25.7 years for the United States and 27.4 years in the United Kingdom) (Centers for Disease Control and Prevention 2009). Thus, in the current study, the age range of 
37 years may be considered one generation or two. For the purposes of the current study, we will consider this span of 37 years as one generation as these data were normally distributed.

\section{Measures}

To measure self-regulation in online learning, the short form of the Online Selfregulated Learning Questionnaire (OSLQ) was employed (Barnard, Lan et al. 2009). The OSLQ is a 24-item scale with a five-point Likert-type response format having values ranging from strongly agree (five) to strongly disagree (one). Higher scores on this scale indicate higher levels of self-regulation in online learning. The short form of the OSLQ was developed from an 86-item long form of the instrument by examining internal consistency and exploratory factor analyses results for data collected from the long form (Lan et al. 2004). The long form of the instrument was developed to reflect a multi-dimensional conception of self-regulated learning as derived from the theoretical framework of Zimmerman (1998). In contrast to the long form of the instrument, the short form consists of six, important constructs of self-regulation in online learning, including: environment structuring; goal-setting; time management; help-seeking; task strategies; and self-evaluation. Table 1 presents the internal consistencies of scores obtained for each subscale for both the pre and post surveys. Nunnally (1978) has suggested that score reliability of 0.70 or better is acceptable when used in basic social science research, such as in this study. Also presented in Table 1, the Pearson's $r$ correlations were calculated across the two surveys for each subscale as a measure of test-retest reliability.

A copy of the OSLQ administered may be obtained from the first author. Table 2 presents an example item from each subscale.

\section{Procedure}

The current study was conducted at an American university, which typically matriculates on an 18-week semester basis during the North American fall and spring. The current study was conducted during the spring 2008 semester at a large, public university located in the southwestern United States. The course delivery format service for this institution was WebCT. WebCT, currently owned by Blackboard, is an online learning course management and delivery system purchased by institutions of higher education for the purpose of online learning. Students were contacted via email address before the study was to take place to inform them of the nature of the study.

Table 1. Internal consistencies for each subscale.

\begin{tabular}{lccc}
\hline Subscale & Pre-survey $\alpha$ & Post-survey $\alpha$ & $r$ \\
\hline Environment structuring & 0.75 & 0.79 & 0.89 \\
Goal-setting & 0.89 & 0.93 & 0.76 \\
Time management & 0.76 & 0.73 & 0.86 \\
Help-seeking & 0.75 & 0.74 & 0.79 \\
Task strategies & 0.76 & 0.77 & 0.90 \\
Self evaluation & 0.72 & 0.73 & 0.88 \\
total scale & 0.86 & 0.86 & 0.90 \\
\hline
\end{tabular}


Table 2. Example Item from each subscale.

\begin{tabular}{ll}
\hline Subscale & Example item \\
\hline Environment structuring & I find a comfortable place to study. \\
Goal-setting & I keep a high standard for my learning in my online courses. \\
Time management & I allocate extra studying time for my online courses because \\
& I know it is time-demanding. \\
Help-seeking & If needed, I try to meet my classmates face-to-face. \\
Task strategies & I prepare my questions before joining in the chat room and \\
discussion. & I communicate with my classmates to find out how I am doing \\
Self evaluation & in my online classes. \\
\hline
\end{tabular}

Once contacted about the study, all students were given the choice to opt out of the study and not to receive further email messages regarding participation. As part of the pre survey, students were asked to confirm that this was their first semester enrolled in courses offered online. Data were downloaded from Survey Monkey, a web-based survey service, into Microsoft Excel format and then imported into SPSS (version 15.0). All analyses were performed in SPSS. The researchers summed the total score for the online self-regulation learning scale for each individual. Values for any missing data were imputed using a linear trend at point estimation available in SPSS. No pattern emerged among the missing data, which were subsequently omitted from analysis.

\section{Analysis}

To answer the first research question, a paired-sample dependent $t$-test was performed to examine whether there were significant differences in overall self-regulatory skills in online learning across the two points. To answer the second research question, paired-sample dependent $t$-tests were performed to examine whether there were significant differences in self-regulatory skills in online learning across the two points on a subscale level. For statistically significant results, values for Cohen's $d$ were calculated as measures of effect size - where a value of 0.20 may be interpreted as a small effect, 0.50 as a medium effect size, and 0.80 and greater as a large effect size (Cohen 1988).

\section{Results}

In answering the first research question, results indicate no significant difference in the overall self-regulatory skills of online learners across the two time points, $t(43)=$ $0.404, p=0.688$. In answering the second research question, the results for each subscale of the self-regulatory skills of online learners will be discussed. With respect to environment structuring, results indicate no significant difference in this subset of self-regulatory skills of online learners across the two time points, $t(43)=1.110$, $p=0.273$. For the subset self-regulatory skill of goal-setting, results indicate no significant difference in this subscale of self-regulatory skills of online learners across the two time points, $t(43)=0.519, p=0.607$. Among the time management subscale of self-regulatory skills, there was no significant difference in self-regulatory skills of 
online learners across the two time points, $t(43)=0.180, p=0.858$. With respect to the help seeking subset of self-regulatory skills, results indicate no significant difference in self-regulatory skills of online learners across the two time points, $t(43)$ $=0.313, p=0.755$. For the subscale of task strategies, there was no significant difference in self-regulatory skills of online learners across the two time points, $t(43)=$ $0.123, p=0.903$. Among the self-evaluation subscale of self-regulatory skills, results indicate no significant difference in self-regulatory skills of online learners across the two time points, $t(43)=0.032, p=0.975$. Table 3 presents the descriptive statistics for each subscale as well as the total scale for both the pre and post surveys.

\section{Discussion}

Results have indicated no significant differences in the online self-regulatory skills of learners across time overall or on the subscale level. These non-significant results may reflect a slower or no development at all of self-regulatory skills in online learners across time. As members of the first generation of online learners, one academic semester may not be long enough to observe significant differences in the online self-regulatory skills of learners according to the theoretical perspective adopted. Additionally, the introduction of a new learning environment alone, the online learning environment, may not be sufficient to trigger significant change in the self-regulatory skills of learners online. Vermetten, Vermunt, and Lodewijks (1999) have indicated that those learners enrolled in their first semester of an online or distance programme may experience friction and may require time to adapt to the new learning environment. This period of adaptation to the online learning environment may inhibit the development of self-regulatory skills among online learners as noted by Vermetten, Vermunt, and Lodewijks (1999). We hypothesise that secondgeneration online learners may be more able to quickly adapt to learning in the online environment than first-generation online learners given technological advances and previous exposure to online environments. Thus, the results of the current study represent basic research indicating that simply immersing a student in an online learning environment does not automatically help a student develop as a self-regulated learner.

The results of the current study are particularly relevant as they suggest, at the very least, the direction of future research with respect to examining the development of self-regulatory skills across time among online learners. Future research should consider examining self-regulated learning skills in view of other metacognitive

Table 3. Descriptive statistics for each subscale.

\begin{tabular}{lcc}
\hline Subscale & Pre survey & Post survey \\
\hline Environment structuring & $M=18.30, S D=2.14$ & $M=17.78, S D=2.27$ \\
Goal-setting & $M=23.95, S D=1.38$ & $M=24.09, S D=1.49$ \\
Time management & $M=11.22, S D=2.31$ & $M=11.30, S D=2.10$ \\
Help-seeking & $M=13.88, S D=2.78$ & $M=13.70, S D=2.34$ \\
Task strategies & $M=12.74, S D=2.87$ & $M=12.67, S D=3.07$ \\
Self evaluation & $M=13.25, S D=2.75$ & $M=13.23, S D=2.55$ \\
total scale & $M=93.68, S D=8.95$ & $M=92.90, S D=9.09$ \\
\hline
\end{tabular}

Note: $M$, mean; $S D$, standard deviation. 
factors such as epistemological beliefs. More importantly, the results of the current study may suggest the diminished impact of a new learning environment as influencing the development of self-regulatory skills of online learners. This possible diminished impact of environment on the development of self-regulated learning suggests that Zimmerman's (1994) social cognitive perspective as self-regulation being the product of the interaction of person, the environment, and their behaviour may require modification. This possible change in theory regarding the development of self-regulatory skills among online learners may include a re-evaluation of what is meant by the term, environment. Learners taking courses offered online or at a distance typically remain in the same physical environment before and after enrolment into an online or distance programme. This lack of having to physically attend classes is, in fact, one of the many advantages of taking a course online or at a distance. The term 'environment' may not be inclusive of online learning environments in the development of self-regulation for learners. Thus, environmental factors may not be all that influential in the development of self-regulatory skills for online learners. These results appear to suggest that personal and behavioural factors may have more influence on the development of self-regulatory skills of online learners than environment.

Smart (1964) first noted the bias against publishing non-significant results, finding that only $9 \%$ of published studies had non-significant results. Csada, James, and Espie (1996) have provided two explanations for why non-significant results are so uniformly not published: these studies are not submitted for publication, or these studies are rejected as result of bias in the review process. While this publication bias may impede the dissemination of non-significant findings in scholarly journals, this does not minimise the importance of findings for theory and practice. Csada, James, and Espie note that the consequence of "not publishing non-significant results can lead to false decisions as to the warrantability of hypotheses" $(1996,593)$, such that readers may be only aware of evidence supporting a hypothesis or theoretical perspective. As a result, a hypothesis or theoretical perspective can begin to hold a privileged status in scholarly literature.

While the theoretical implications of this study are important, the implications for practice for online learning are equally relevant such that Chief Academic Officers at institutions of higher education as part of the annual Sloan-C Online Survey have noted that "a barrier to widespread adoption of online learning" was the fact that "students need more discipline to succeed in online courses" (Allen and Seaman 2006, 13). These findings that indicate a lack of significant development of self-regulatory skills among first time online learners across time suggest the need for interventions that foster self-regulatory skills in the online learning environment. The online learning environment can provide opportunities for first-time online learners to develop self-regulatory skills and thus improve academic outcomes. These opportunities can include, but are not limited to, providing students with: an editable, online calendar by which they can note upcoming assignments and deadlines; a blog by which students can access resources and discuss the course with other students; and a troubleshooting web page to help students with frequently asked questions. The tools that educators can provide to first time online learners to foster their self-regulatory behaviours are limitless as technologies develop. As educators, we must intentionally develop student self-regulatory skills through the design of the online learning environment. The results of this study indicate the development of self-regulatory skills in the online learning environment must not be treated as passive. 


\section{References}

Allen, I.E., and J. Seaman. 2006. Making the grade: Online education in the United States. Needham, MA: Sloan-C.

Ally, M. 2004. Foundations of educational theory for online learning. In The theory and practice of online learning, ed. T. Anderson, 15-44. Edmonton, CA: Athabasca University Press.

Arbaugh, J.B. 2004. Learning to learn online: A study of perceptual changes between multiple online course experiences. The Internet and Higher Education 7, no. 3: 169-82.

Bandura, A. 1986. Social foundations of thought and action: A social cognitive theory. Englewood Cliffs, NJ: Prentice-Hall.

Bandura, A. 1997. Self-efficacy: The exercise of control. New York: Freeman.

Barnard, L., W.Y. Lan, S.M. Crooks, and V.O. Paton. 2008. The relationship of epistemological beliefs with self-regulatory skills in the online course environment. Journal of Online and Learning Teaching 4, no. 3: 261-6.

Barnard, L., W.Y. Lan, Y.M. To, V.O. Paton, and S.L. Lai. 2009. Measuring self-regulation in online and blended learning environments. The Internet and Higher Education 12: 1-6.

Barnard, L., V.O. Paton, and W.Y. Lan. 2008. Online self-regulatory learning behaviors as a mediator in the relationship between online course perceptions with achievement. International Review of Research in Open and Distance Learning 9, no. 2: 1-11.

Centers for Disease Control and Prevention. 2009. National vital statistics system. http:// www.cdc.gov/nchs/births.htm.

Cohen, J. 1988. Statistical power analysis for the behavioral sciences. 2nd ed. Hillsdale, NJ: Lawrence Erlbaum Associates.

Csada, R.D., P.C. James, and R.H. Espie. 1996. The ‘file drawer problem' of non-significant results: Does it apply to biological research? Oikos 76, no. 3: 591-3.

Digest of Educational Statistics. 2007. Table 175: Total fall enrollment in degree-granting institutions, by attendance status, sex of student, and control of institution: Selected years, 1947 through 2005. http://nces.ed.gov/programs/digest/d06/tables/dt06_175.asp.

Fisher, M., and D.E. Baird. 2005. Online learning design that fosters student support, selfregulation, and retention. Campus-Wide Information Systems 22, no. 5: 88-107.

Kramarae, C. 2001. The third shift: Women learning online. Washington, DC: American Association of University Women Educational Foundation Press.

Lan, W.Y., R. Bremer, T. Stevens, and G. Mullen. 2004. Self-regulated learning in the online environment. Paper presented at the annual meeting of the American Educational Research Association, April, in San Diego, CA.

Lynch, R., and M. Dembo. 2004. The relationship between self-regulation and online learning in a blended learning context. International Review of Research in Open and Distance Learning 5, no. 2: 1-16.

Meece, J.L. 1994. The role of motivation in self-regulated learning. In Self-regulation of learning and performance: Issues and educational applications, ed. D.H. Schunk and B.J. Zimmerman, 24-44. Mahwah, NJ: Lawrence Erlbaum.

Nota, L., S. Soresi, and B.J. Zimmerman. 2004. Self-regulation and academic achievement and resilience: A longitudinal study. International Journal of Educational Research 41, no. 3: $198-215$.

Nunnally, J.C. 1978. Psychometric theory. 2nd ed. New York, NY: McGraw-Hill.

Schunk, D.H. 2001. Social cognitive theory and self-regulated learning. In Self-regulated learning and academic achievement, ed. B.J. Zimmerman and D.H. Schunk, 125-52. 2nd ed. Mahwah, NJ: Lawrence Erlbaum.

Schunk, D.H., and B.J. Zimmerman. 1998. Self-regulated learning: From teaching to selfreflective practice. New York, NY: Guilford Press.

Severiens, S., G. Ten Dam, and B.V.H. Wolters. 2001. Stability of processing and regulation strategies: Two longitudinal studies on student learning. Higher Education 42, no. 4: 437-53.

Smart, R.G. 1964. The importance of negative results in psychological research. Canadian Psychology 5: 225-32.

Vermetten Y.J., J.D. Vermunt, and H.G. Lodewijks. 1999. A longitudinal perspective on learning strategies in higher education - different view-points towards development. British Journal of Educational Psychology 69, no. 2: 221-42. 
Vygotsky, L.S. 1992. Educational psychology. Miami, FL: St Lucie Press. Originally published in 1926.

Zimmerman, B.J. 1994. Dimensions of academic self-regulation: A conceptual framework for education. In Self-regulation of learning and performance, ed. D.H. Schunk and B.J. Zimmerman, 3-21. Hillsdale, NJ: Lawrence Erlbaum.

Zimmerman, B.J. 1998. Academic studying and the development of personal skill: A selfregulatory perspective. Educational Psychologist 33: 73-86.

Zimmerman, B.J., and D.H. Schunk. 2001. Self-regulated learning and academic achievement: Theoretical perspectives. 2nd ed. Mahwah, NJ: Lawrence Erlbaum Associates. 